University of Nebraska - Lincoln

DigitalCommons@University of Nebraska - Lincoln

$10-12-2020$

\title{
Seasonality in Fed Cattle Transactions and the Role of Negotiated Cash
}

Elliott James Dennis

University of Nebraska - Lincoln, elliott.dennis@unl.edu

Follow this and additional works at: https://digitalcommons.unl.edu/ageconfarmmgmt

Part of the Agribusiness Commons, Entrepreneurial and Small Business Operations Commons, Management Information Systems Commons, Other Business Commons, and the Other Economics Commons

Dennis, Elliott James, "Seasonality in Fed Cattle Transactions and the Role of Negotiated Cash" (2020). Extension Farm and Ranch Management. 53.

https://digitalcommons.unl.edu/ageconfarmmgmt/53

This News Article is brought to you for free and open access by the Agricultural Economics Department at DigitalCommons@University of Nebraska - Lincoln. It has been accepted for inclusion in Extension Farm and Ranch Management by an authorized administrator of DigitalCommons@University of Nebraska - Lincoln. 


\title{
Seasonality in Fed Cattle Transactions and the Role of Negotiated Cash
}

\author{
Elliott Dennis, Assistant Professor \& Livestock Extension Economist \\ Department of Agricultural Economics, University of Nebraska-Lincoln
}

October 12,2020

This was first published by In the Cattle Markets.

Alternative Marketing Arrangements (AMA) have once again taken center stage in the cattle market over the last several weeks. It is common knowledge that the use of AMAs varies by geographical region with Southern Plains feedlots using a larger share relative to Northern Plains feedlots. A long-standing issue is whether each geographical region is contributing a perceived appropriate amount of negotiated cash trade to aid in price discovery. This issue has intensified as the national level of negotiated cattle continues to decline. Lower cash prices and increased volatility due to COVID-19 government quarantine measures and the Holcomb Fire have appeared to intensify this issue among market participants.

In response to historically low cash prices, some industry organizations petitioned the government for further transparency and regulation in the feedlot-packer interface. The first proposed government legislation was the "50-14" rule led by Chuck Grassley (R-IA) and Senator Jon Tester (D-MT) which sought to mandate large-scale packers to procure a minimum of $50 \%$ of all cattle purchased via negotiated cash for harvest in 14 days. There was strong industry response against mandating a level of negotiated cash trade, especially at 50\%. The second, and most recent, was a bill introduced by Senator Deb Fisher (R-NE) that would authorize USDA to set establish regional mandatory minimum thresholds of negotiated cash trades by geographical region with industry comment. It would also authorize USDA to set up a contract library like the one currently available in the hog market. Both bills aim to increase the amount of regional cash negotiated trade which in turn would increase negotiated cash prices received by producers.

However, the supply of fed cattle and demand for wholesale beef determines the price of fed cattle. To increase negotiated fed cattle prices, both proposed bills would either need to reduce the supply of fed cattle or increase the demand for wholesale beef. These rules would increase negotiated cash transactions helping in price discovery in each week but are unlikely to affect the underlying fed cattle market supply and demand condition to increase the local cash price. If these laws had been in place prior to either the Holcomb Fire or COVID-19 it is unlikely they would have changed packing plants' ability to process cattle (supply from feedlots) or food services' demand for beef. Currently national cattle on feed numbers suggest that the backlog, resulting from government quarantines and COVID-19 cases in packing plants, has almost been completely worked through.

There have been two primary ways the industry has reacted to these bills. First, the industry tried to increase the amount of negotiated cattle in the market using the proposed "Bid-the-Grid" program. This led to an unprecedented amount of negotiated grid cattle being sold, most notably 
in Kansas. For example, historically the share of weekly cattle being sold via negotiated grid, either live or dressed, is $5 \%$. In one week, negotiated grid spiked to $20 \%$, a level not seen in $10+$ years. Since then, it has returned to historical levels. The second reaction has been to develop and advocate for a voluntary framework. This framework would work to have each geographical region increase the share of negotiated cattle if certain levels or "triggers" were reached. This is the industry's preferred method prior to government legislation. The ability for voluntary market participation is likely already in the market. Producers choose to engage in AMAs largely because there are market incentives to do so. To get feeders to move away from AMAs towards negotiated cash the market incentives to do so must be as least as large as those currently offered under AMAs. For example, during the Holcomb fire Nebraska producers, who historically sell a large amount of negotiated cattle, switched over to more formula/grid sales. One explanation for this is that producers did not believe their cattle quality was being valued in the market. One way to try and (re)capture this additional perceived value was to sell cattle on formula/grid. After the Holcomb Fire cattle sold via formula/grid returned to historical levels

One issue potentially confounding understanding the role of negotiated trade is that often cattle sold by transaction (i.e. negotiated cash, forward contract, formula, and negotiated grid) report a combined live and dressed trade (Figure 1). More cattle are sold via negotiated cash on a live basis. From 2016-2020 approximately 60\% of all cattle sold on a live basis were negotiated cash (Figure 2). Compare this to the $10 \%$ sold dressed via negotiated cash (Figure 3). The share of dressed cattle in the overall monthly cattle trade between 2010 and 2019 is about $70 \%$. Thus, if the trend continues towards selling more cattle dressed then the relative share of negotiated cash will likely continue to decline.

So what has been happening to the share of cattle transactions (i.e. negotiated cash, forward contract, formula, and negotiated grid) sold on a live basis during COVID-19? In short, there has been little change in negotiated cash as a share of all cattle transactions, on average nationally since January 1, 2020. Although there appears to be some regional differences with Northern Plains states experiencing slightly more volatility in the share of negotiated trade compared to Southern Plains states. Like most price series, cattle transactions are seasonal. Figure 4 displays the seasonality of negotiated cash (live + dressed) as a share of all cattle transactions nationally for 2015-2019, 2019, and 2020. There has been no change to the seasonality patterns of negotiated cash trade in 2020 compared to the five-year average. The decline in Q3:2019 and Q4:2019 came in large part from the Texas-Oklahoma-New Mexico region not reporting sales because confidentiality requirements were not met. The drop in negotiated cash trade began to fall prior to the Holcomb Fire incident in August 2019. Thus, it is unlikely that the Holcomb Fire caused the lack of reporting but could have prolonged it. Figure 5 shows the seasonality of negotiated cash as a percentage of all live cattle transactions. Year-to-date in 2020, more cattle have been sold live via negotiated cash compared to the five-year average. Even during the government quarantine and packing plant closures (March-August), on average, the percentage of cattle sold live via negotiated cash was above the five-year average. Figures 4 and 5 show some graphical evidence that the Holcomb Fire and COVID-19 market disruptions are unlikely to have affected the national percentage of cattle sold (live, dressed, or live+dressed) via negotiated cash. 
Both proposed bills put forth by the U.S. Senate have stated that need for more price discovery due to the Holcomb Fire and COVID-19 market disruptions. Figures 1-5 graphically show that the national level of negotiated cash was likely not significantly impacted by either market disruptions. The current concern surrounding AMA's (i.e. formula/grid pricing) has more to do with lower cash prices received by producers due to market reactions to major market disruptions than the role of AMA's role in thinly traded markets. While both bills would bring increased negotiated cash price discovery and transparency in the feedlot-packer market interface, neither are likely to increase the cash price received by producers since they do not fundamentally change the supply of fed cattle nor the demand for wholesale beef. Further, it is unlikely that if these bills were implemented prior to either the Holcomb Fire or COVID-19 it would have prevented the backlog in cattle nor affected the demand for wholesale beef. If implemented, these policies would create additional transparency but potentially creating increased costs and reducing profitability for the entire beef complex. Consistent with the economic theory of derived demand, the additional costs of these policies are likely to predominately carried by the cow-calf industry. 


\section{Supporting Figures}

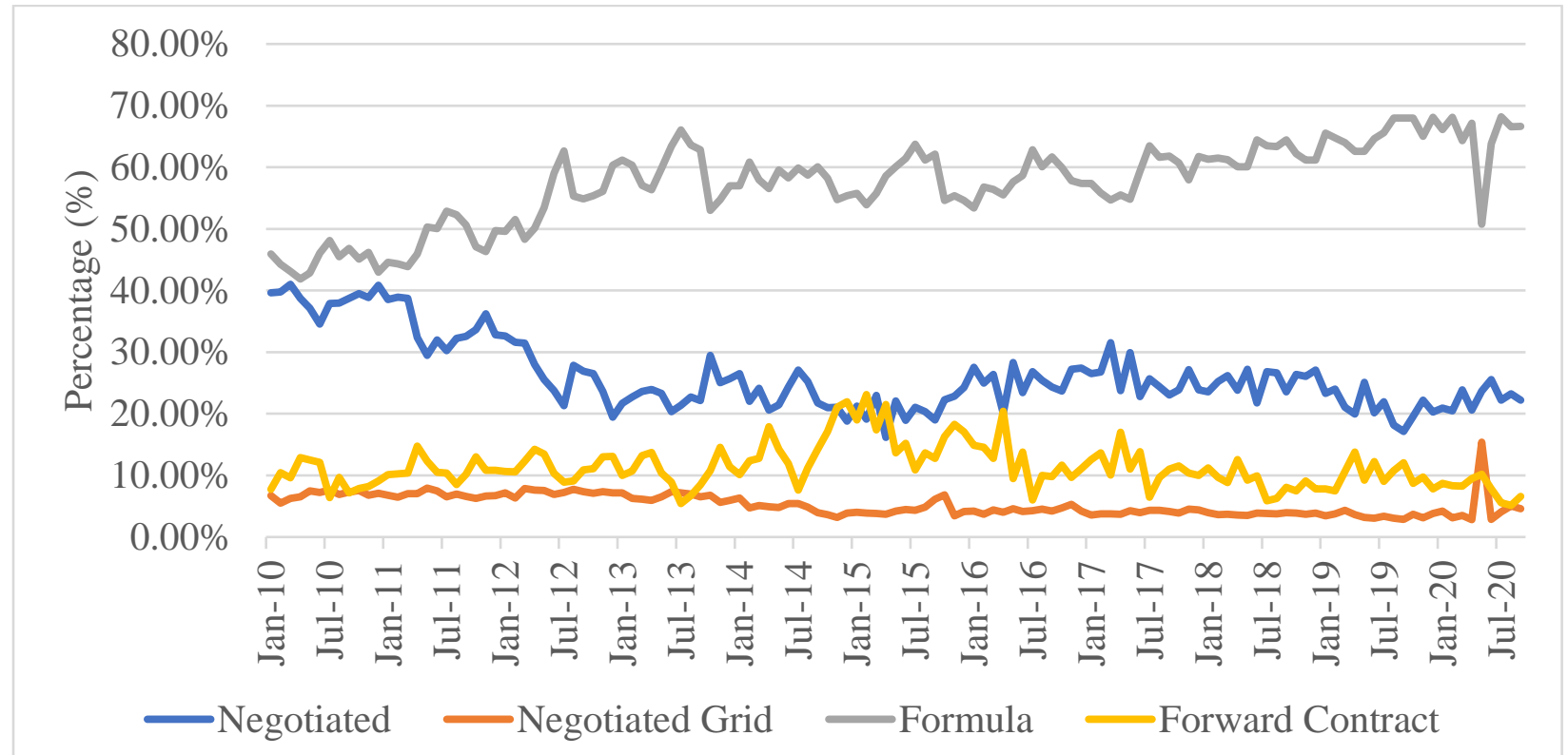

Figure 1. Historical Percentage of All Cattle Transactions (Live + Dressed), 2010-2020

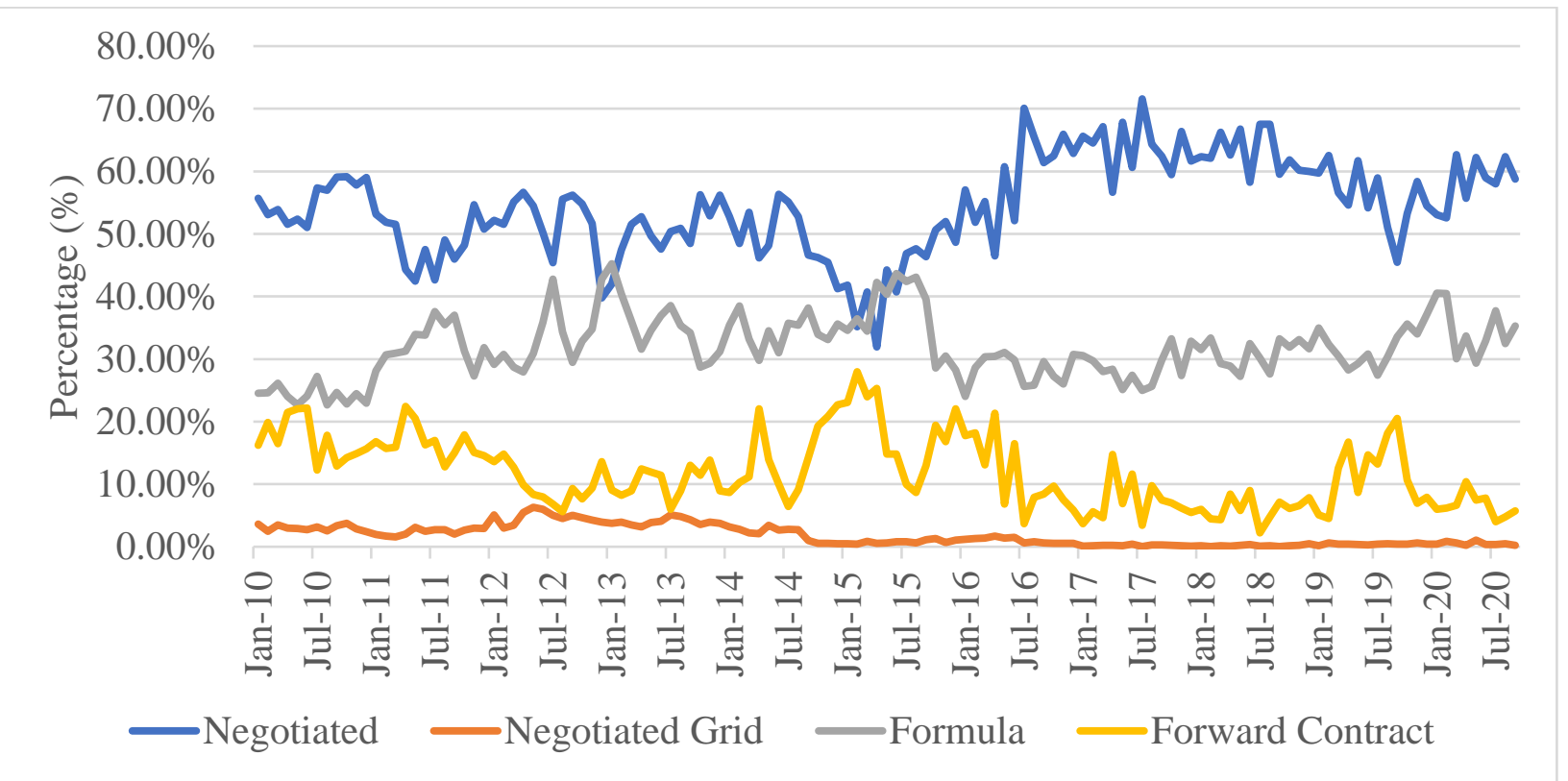

Figure 2. Historical Percentage of Live All Cattle Transactions, 2010-2020 


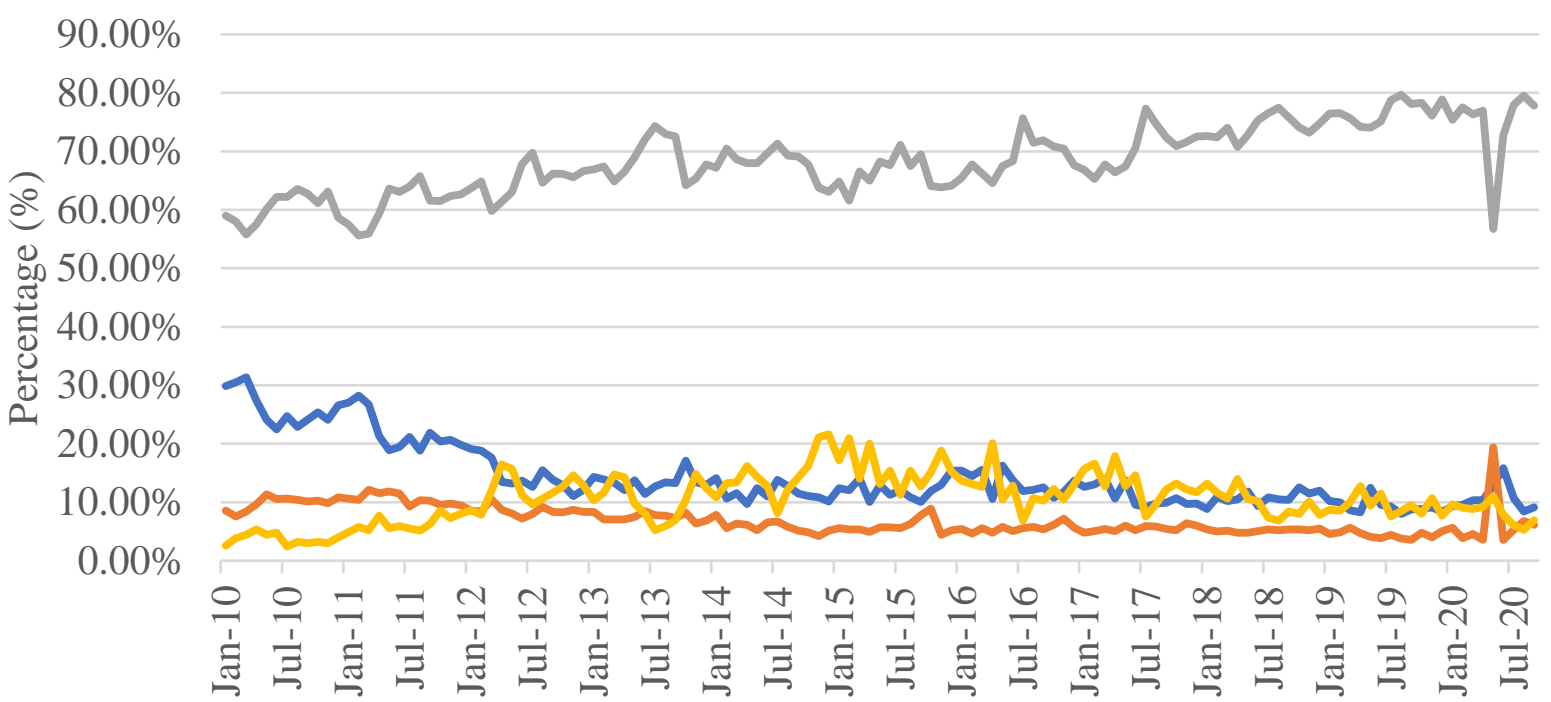

- Negotiated - Wegotiated Grid Formula - Forward Contract

Figure 3. Historical Percentage of Dressed All Cattle Transactions, 2010-2020

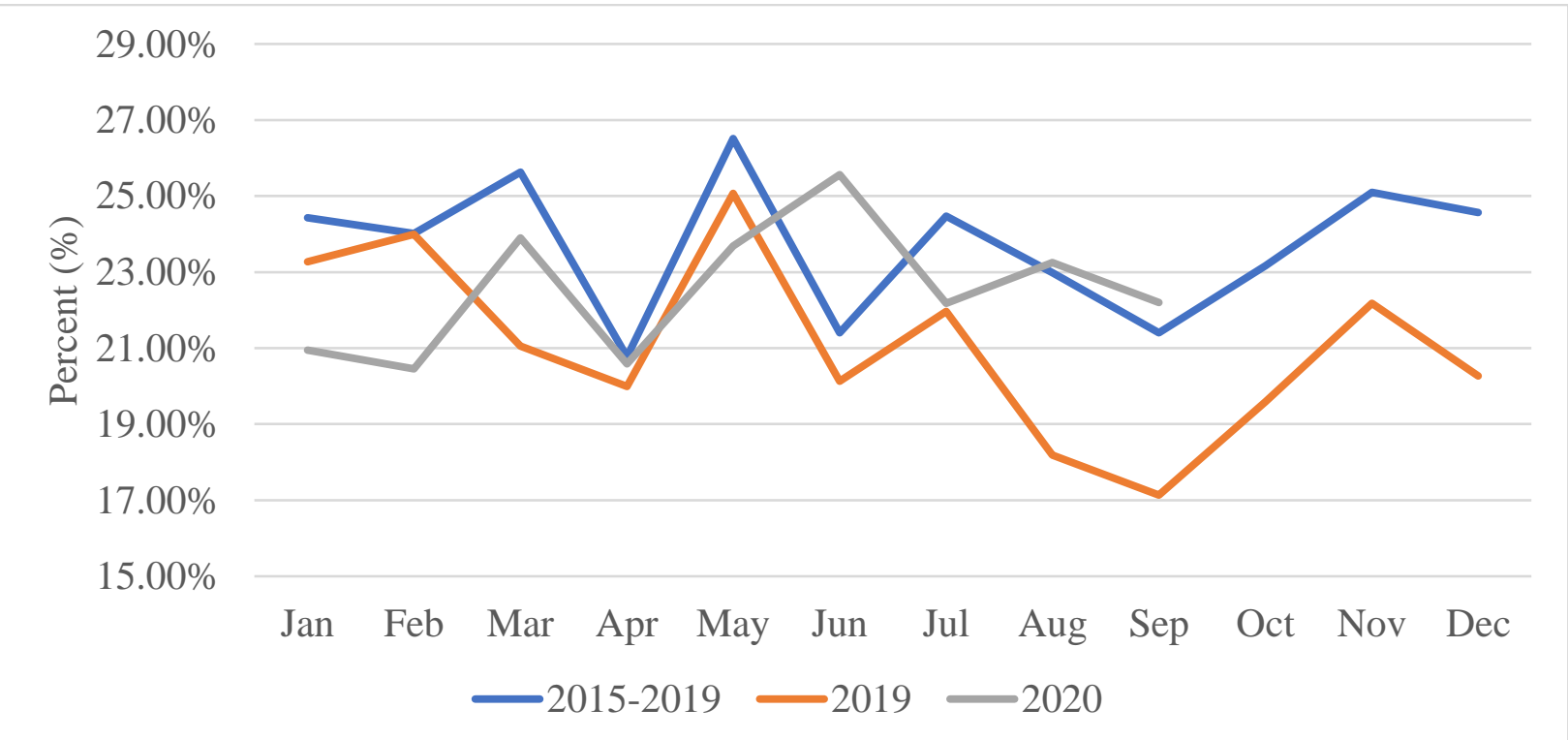

Figure 4. Seasonality in the Percentage of Negotiated Sales (Live + Dressed) as a Percent of All Cattle Transactions 


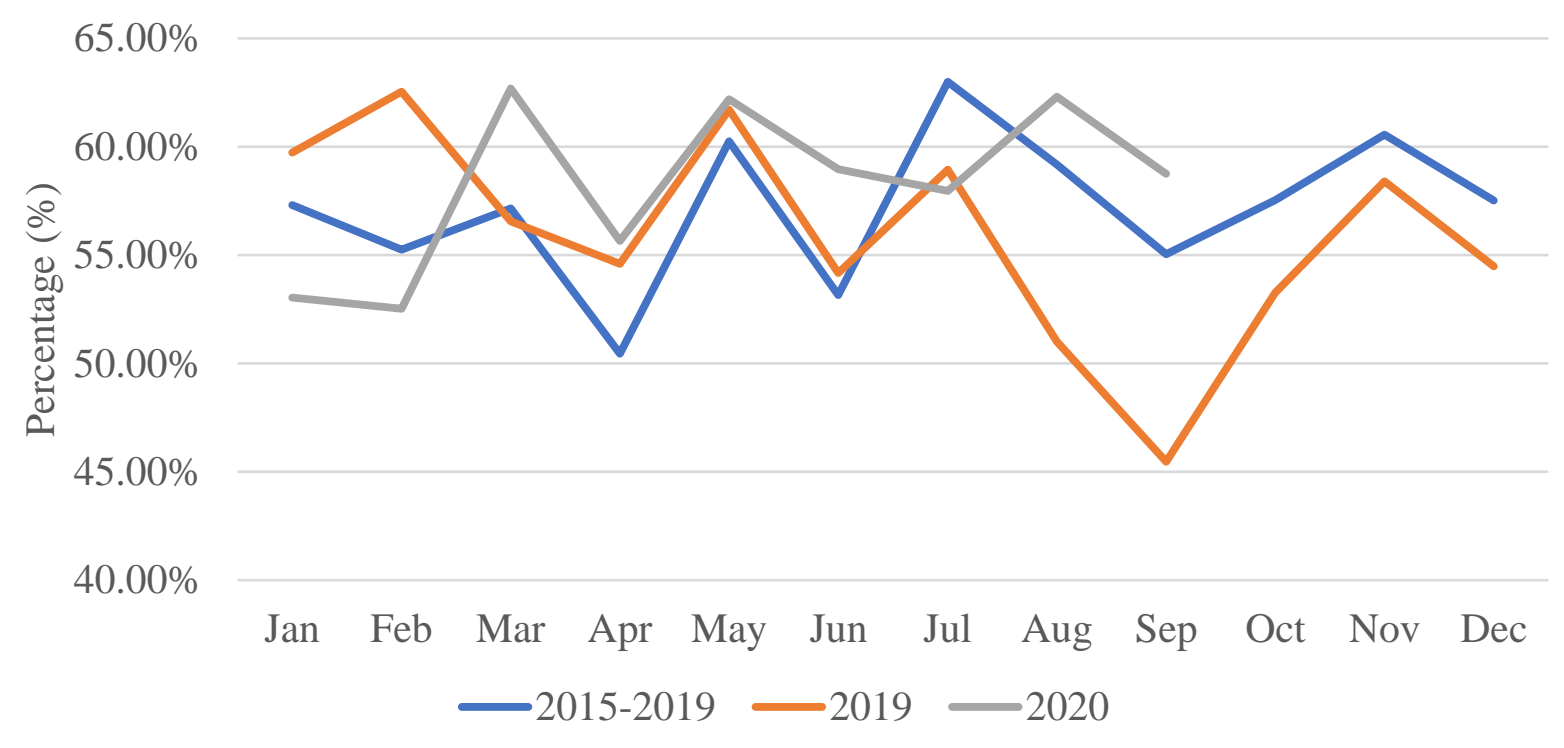

Figure 5. Seasonality in the Percentage of Negotiated Sales Sold on a Live Weight Basis 